\title{
Jack Freed: On the Occasion of His 80th Birthday
}

\author{
Sunil Saxena ${ }^{1} \cdot$ Aharon Blank $^{2}$ \\ Published online: 8 October 2018 \\ (c) Springer-Verlag GmbH Austria, part of Springer Nature 2018
}

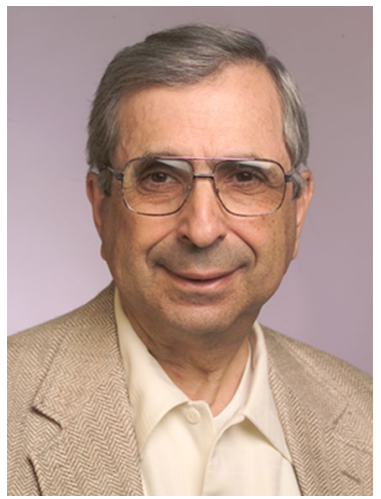

It is with great pleasure that we present the magnetic resonance community with this special issue commemorating the 80th birthday of Prof. Jack H. Freed. J. H. Freed, Professor Emeritus of Chemistry at Cornell University, was born in New York City, on April 19, 1938. After graduating from Stuyvesant High School (1954), he attended Yale University, receiving his B.E. degree in 1958, graduating first in his class with the highest honors. He pursued his graduate studies at Columbia University with Professor G. K. Fraenkel and received his M.S. in 1959 and his Ph.D. in 1962. During 1962-1963 Dr. Freed was a Postdoctoral Fellow at Cambridge University. In 1963 he accepted a faculty appointment at Cornell University, where he has spent his subsequent career (Assistant Professor, 1963-1967; Associate Professor, 1967-1973; Professor, 1973-2007; Frank and Robert Laughlin Professor of Physical Chemistry (2007-2016); and Professor Emeritus, 2016-). He has been director

Sunil Saxena

sksaxena@pitt.edu

$\triangle$ Aharon Blank

ab359@technion.ac.il

1 Department of Chemistry, University of Pittsburgh, Pittsburgh, PA 15260, USA

2 Schulich Faculty of Chemistry, Technion, Israel Institute of Technology, Haifa 32000, Israel 
of the National Biomedical Center for Advanced ESR Technology (ACERT) since 2001.

Prof. Freed is one of the true pioneers in the field of magnetic resonance and undoubtedly a leader in electron spin resonance (ESR). Almost any major topic of research in ESR, both theoretical and experimental, has been either explored or described by one of the many papers he published. His seminal contribution to the field started during his graduate studies with Prof. Fraenkel in the early 1960s, with a paper describing the anomalous alternating linewidths in the ESR spectra of anion radicals. This work led to what is now known as the Freed-Fraenkel theory of ESR linewidths and formed the basis of his subsequent comprehensive theory of the phenomena of ESR saturation and electron-nuclear double resonance (ENDOR) later in the 1960s. In this context, it is important to note that his important insights revealed in a series of papers from the late 1960s, entitled "Theory of Saturation and Double Resonance Effects in ESR Spectra", led to the development and applications of the electron-nuclear triple resonance (TRIPLE) technique.

While initially the main focus of Prof. Freed's work was of a theoretical nature, soon after he came to Cornell he also started to work on advanced experimental aspects of ESR, such as continuous wave and pulsed electron-electron double resonance (ELDOR). In parallel with setting up a first class experimental laboratory, he continued to dwell deep into ESR theory. The question that was high on the agenda of the scientific community was how to interpret the strange, seemingly almost arbitrary, shape variations apparent in the ESR spectra of stable radicals in solution, especially when their motion is restricted. The solution came out in the form of Prof. Freed's famous method for ESR lineshape calculations using the stochastic Liouville equation (SLE). The numerical solution of the resulting expressions turned out to be extremely computationally intensive, especially with the compute power available in the late 1970s and early 1980s, which necessitated a range of mathematical developments, unique in their own, just to cope with this aspect of the problem. Eventually, this SLE approach matured in the late 1990s and is now used extensively to interpret many of the ESR spectra obtained in many laboratories worldwide.

During the 1980s and the 1990s, the laboratory of Prof. Freed pioneered a pack of new ESR experimental methodologies, such as two-dimensional pulsed ESR and high-field ESR. The former included pulse sequences that were adapted from NMR, such as COSY and SECSY, but were considered an impossible feat for ESR due to its much shorter relaxation times, much higher microwave frequencies, and the complicated theory needed to properly interpret the results of these experiments. Prof. Freed and his group overcame all these challenges and this has resulted in techniques such as 2D ELDOR, which serves as a cornerstone in the exploration of molecular dynamics. In the late 1990s, he also published the first few papers that showed the potential of ESR to measure large interspin distances.

At the turn of the new millennium, the research of Prof. Freed received a huge boost with the establishment of his NIH-funded advanced center for ESR technology (ACERT). Within the framework of ACERT activity, many new methodologies were developed, improved, and applied primarily to a variety of biologically related research issues. This includes methods such as double quantum coherence ESR for distance determination, pulsed high-field ESR, ESR microscopy, and multifrequency 
ESR studies to reveal the complicated dynamics of macromolecules at different time scales and a variety of signal processing methods to analyze and denoise ESR data. This wide arsenal of methods has been used in recent years to solve long-standing questions in structural biology, leading to several impactful papers in Nature, Science, and PNAS.

Through his works Prof. Freed continues the excellent scientific tradition that traces back to the sixteenth century. If we trace back his "academic ancestors", we find that the mentor of his PhD instructor (Prof. Fraenkel) was the Nobel Laureate Prof. Peter Debye. In turn, Debye's instructor was the great physicist, Prof. Arnold Sommerfeld, who was himself instructed by the German mathematicians Prof. Ferdinand Lindemann. The latter trained under Prof. Felix Christian Klein. From here on, we find famous mathematicians such as Rudolf Lipschitz, whose instructor was Gustav Peter Lejeune Dirichlet with his two academic "fathers" Fourier and Poisson, and then Lagrange and Laplace, leading to d'Alember: overall, a truly remarkable academic tree which evidently led to a truly remarkable scientific career.

Prof. Freed has received many honors for his scientific activity, as listed below, and has instructed almost 40 graduate students and 70 postdocs (listed below). Clearly, this short preface cannot accommodate all the scientific achievements of Prof. Freed. Yet, we hope this serves as an appetizer for reading the papers gathered in the two volumes of this special issue, many of which touch upon the subjects that were at the focus of Prof. Freed's activity. Before concluding, we want to wish Jack many more years of good health and scientific creativity and much "Nachath" from his family-his ever-loving wife Renée, his daughters Denise and Nadine and his lovely grandchildren.

\section{Biographical Sketch}

J. H. Freed, Professor Emeritus of Chemistry at Cornell University, was born in New York City, on April 19, 1938. After graduating from Stuyvesant High School (1954), he attended Yale University, receiving his B.E. degree in 1958, graduating first in his class with the highest honors. He pursued his graduate studies at Columbia University with Professor G. K. Fraenkel and received his M.S. in 1959 and his Ph.D. in 1962. During 1962-1963, Dr. Freed was a Postdoctoral Fellow at Cambridge University. In 1963 he accepted a faculty appointment at Cornell University, where he has spent his subsequent career (Assistant Professor, 1963-1967; Associate Professor, 1967-1973; Professor, 1973-2016; Professor Emeritus, 2016-); Frank and Robert Laughlin Professor of Physical Chemistry (2007-); and became Professor Emeritus as of July 1, 2016. He has been director of the National Biomedical Center for Advanced ESR Technology (ACERT) since 2001.

Professor Freed is a world-renowned expert in the field of magnetic resonance, especially electron-spin resonance (ESR). He is the author or co-author of over 400 publications.

\section{List of Fellowships, Awards, and Professional Activities}

Honorary U.S. Ramsay Memorial Fellow (1962-1963) 
NSF Postdoctoral Fellow Cambridge University (1962-1963)

A.P. Sloan Foundation Fellow (1966-1968)

Visiting Scientist, U.S.-Japan Cooperative Science Program, Tokyo University (1969)

Senior Weizmann Fellow, Weizmann Institute of Science (1970)

Guest Professor, Aarhus University (1974)

Chairman, Gordon Research Conference on Magnetic Resonance (1975)

Board of Editors, Journal of Chemical Physics (1976-1978)

Fellow of the American Physical Society (1976)

Visiting Professor, University of Geneva (1977)

Visiting Professor, Delft University of Technology (1978)

Editorial Advisory Board, Journal of Physical Chemistry (1979-1983)

Buck-Whitney Award of the American Chemical Society (1981)

John Simon Guggenheim Memorial Fellow (1984-1985)

Visiting Professor, L'École Normale Supérieure, Paris (1984-1985)

Advisory Editorial Board, Chemical Physics Letters (1988-1990)

Bruker Award and Lecturer, The Royal Society of Chemistry (London, 1990)

Editorial Board, Applied Magnetic Resonance (1990-2016)

Fellow of the Institute for Advanced Studies, The Hebrew University of Jerusalem (1990)

Visiting Professor, University of Padua (1991)

Gold Medal Award of the International Electron Spin Resonance Society (1994)

Editorial Board, Magnetic Resonance Review (1994-2000)

Fellow of the American Academy of Arts and Sciences (1994)

Irving Langmuir Prize of the American Physical Society (1997)

Charles A. MacDowell Lecturer in Chemical Physics, University of British Columbia (1997)

Distinguished Visiting Professor, Yamagata University (1998)

International Zavoisky Prize, Zavoisky Institute, Russian Academy of Sciences (1998)

Honorary Member, National Magnetic Resonance Society of India (2001)

J.H. Freed Festschrift Issue of Journal of Physical Chemistry (July, 2004)

External Advisory Board National High Magnetic Field Laboratory (2006-)

Associate Editor, Journal of Magnetic Resonance (2007-2010)

Visiting Scientist, University of Oxford (2007-2013)

E. Bright Wilson Award of the American Chemical Society (2008)

Inaugural Fellow of the International Society of Magnetic Resonance (2008)

President of the International EPR/ESR Society (2008-2010)

Israel Pollak Distinguished Lectureship, Technion, Israel (2009)

Fellow, Royal Society of Chemistry (FRSC) (2009)

Fellow, American Association for the Advancement of Science (2009)

ISMAR Prize, International Society of Magnetic Resonance (2013)

Joel Hildebrand Award of the American Chemical Society (2014)

Voevodsky Prize (2017)

Fellow of the International EPR/ESR Society (2017) 


\section{Grad Students}

P. Glenn Barkley

David Bazell

Jaya Bhatnagar

Gerald V. Bruno

Siddarth Chandrasekaran

Yun-Wei Chiang

Henry D. Connor

Antonio da Costa Filho

Keith A. Earle

Michael P. Eastman

Stephen A. Goldman

Jeff Gorcester

Pranav Gupta

Robert G. Kooser

John C. Lang, Jr.

Sanghyuk Lee

Daniel S. Leniart

Yan Lou

Glenn L. Millhauser

Akbar Nayeem

Carl F. Polnaszek

Aritro Sinha Roy

Dipanjan Samanta

Sunil K. Saxena

Deniz Sezer

David J. Schneider

Leslie J. Schwartz

Yeon-Kyun Shin

Andrew K. Smith

Madhur Srivastava

Stephen Wagner

Dajiang Xu

Stephen A. Zager

Walter Zeltner

Gary P. Zientara

Ziwei Zhang

Postdoctoral Associates, Visiting Scientists, and Collaborators

\section{Postdoctoral Associates}

Jeff P. Barnes

Nikolas P. Benetis
Nick P. Bigelow

Aharon Blank

Wolfgang Buchner

David E. Budil

Robert F. Campbell

Timothée Chauviré

Laura Ciani

David A. Cleary

Richard H. Crepeau (became Sr. Res.

Assoc.)

M. Ramachandra Das

John S. Denker

Boris Dzikovski (became Sr. Res.

Assoc.)

Uzi Eliav

Alberta Ferrarin

John M. Frank (became Res. Assoc.)

Barbara Fresch

Dan Gamliel

Ming Tao Ge

Elka R. Georgieva (became Sr. Res.

Assoc.)

Wulf Hofbauer

Joseph P. Hornak

James S. Hwang

Lian-Pin Hwang

Dan lgner

Eva Igner

Burgess R. Johnson

Leela Kar

Yoshiya Kera

Alex Liqi Lai (became Res. Assoc.)

Keun-Ho Lee

Laurent P. Levy

Zhichun Liang (became Sr. Res.

Assoc.)

Wuu-Jyi Lin

Dmitri Lukoyanov

W. Bryan Lynch

Ronald P. Mason

Eva Meirovitch

Giorgio Moro

Alex A. Nevzorov

Mark Nilges

Sergei Patchenko

Baldev Patyal 
J. Boiden Pedersen

Antonino Polimeno

Shankar B. Rananavare

Venkata K. S. Rao

Ayelet Regev

Diane Richardson

Gunther Rist

Tim R. Saarinen

Yuhei Shimoyama

Dae Ho Shin

Masaru Shiotani

Alex I. Smirnov

Bryan W. Statt

Arthur E. Stillman

Hisao Tanaka

Dmitri S. Tipikin

Vitaly Tugarinov

Galina Ulanova

Walter V. Volland

Qi Wang

William A. Wassam, Jr.

Bernard Yurke

Chorng-tao Yu

\section{Senior Visitors}

Antonije Dulcic

Rudolph Durny

Uwe Ewert

Vladimir Jidkov

Josef K. Moscicki

Boris Naumov

Yasunori Ohba

Venkata G. K. M. Pisipati

Arnold Raitsimring

Kev M. Salikhov

Venkata S.S. Sastry

Musti J. Swamy

Kashyap V. Vasavada

Senior Research Associates

Peter P. Borbat

Richard H. Crepeau

Curt R. Dunnam, engineer

\section{Senior Collaborators}

George K. Fraenkel-Ph.D. Advisor

Christopher A. Alabi

C. Lindsay Anderson

Barbara Baird

Vincenzo Barone

R. Lynn Belford

Maina Bennati

Alexandra Bilwes

Albert M. Bobst

Olga Boudker

H. Alex Brown

Robert Brittl

Louis-Claude Brunel

Robert G. Bryant

James M. Burlitch

Samuel Butcher

Chi-Chang Chu

Tom G. Clark

Robert B. Clarkson

Brian Crane

Susan Daniel

John M. Deutch

James L. Dye

Dale E. Edmondson

Peter Edwards

David Eliezer

Scott Emr

Gerald W. Feigenson

Brett Fors

Betty Gaffney

Kevin H. Gardner

Elizabeth D. Getzoff

Lila M. Gierasch

Oleg Grinberg

Songi Han

Jeff Harmer

Ekaterina E. Heldwein

Brian Hoffman

David Holowka

Wayne L. Hubbell

James S. Hyde

Ken Kirschenbaum

Jean-Pierre Korb

Josef Kovaleski 
Danuta Kruk

David M. Lee

Hening Lin

Vsevolod Livshits

Michael G. Malkowski

John A. Marohn

Saba Mattar

Fred Maxfield

Ann McDermott

Hassane S. Mchaourab

Sushil K. Misra
Pier-Luigi Nordio

Chris K. Ober

Jan Pilar

Andrzej Rajca

Benoit Roux

Harold A. Scheraga

Charles P. Scholes

Hal Swartz

Wolfgang Trommer

Francis I. Valiyaveetil

Gary R. Whittaker 